\title{
Pyrene biodegradation capability of two different microalgal strains
}

\author{
Aldaby E.S.E. and Mawad A.M.M.* \\ Botany and Microbiology Department, Faculty of Science, Assiut University, 71516 Assiut, Egypt \\ Received: 14/05/2018, Accepted: 22/10/2018, Available online: 25/10/2018 \\ *to whom all correspondence should be addressed: e-mail: a.mawad@aun.edu.eg \\ https://doi.org/10.30955/gnj.002767
}

\begin{abstract}
Biological treatment is one of the most preferable strategies to complete and safe removal of pollutants. Pyrene (PY) is the first member of high molecular weight polycyclic aromatic hydrocarbons (HMW-PAHs) that represents various concerns to biological life and human health. In this study, two different algal strains exhibited different capability to degrade PY along 30 days of incubation in the light. Dry weight, total chlorophyll, and carotenoids were growth parameters that were determined to detect robust of two algal strains to get used of PY as a source of carbon. Oscillatoria sp. could degrade $95 \%$ while Chlorella sp. could degrade $78.71 \%$ of PY $(50 \mathrm{mg} / \mathrm{L})$ after 30 days of incubation. Both algal strains could completely remove 10 and $30 \mathrm{mg} / \mathrm{L}$ of PY. On the other hand, the degradation capability of Oscillatoria sp. was significantly exceeded than Chlorella sp. under the same incubation condition and at (50 and $100 \mathrm{mg} / \mathrm{L}$ ) of PY.
\end{abstract}

Keywords: Carotenoids, Chlorella sp., chlorophyll, kinetics, Oscillatoria sp., PAHs, pyrene.

\section{Introduction}

Polycyclic aromatic hydrocarbons (PAHs) are considered the most serious environmental pollutants. According to their chemical structure, they consist of two or more fused benzene rings in linear, angular, or cluster arrangements. They characterized as a persistent compounds in the environment due to their low water solubility, relative stability or low volatility, and resistance to biological degradation (Sartoros et al., 2005). They accumulate in the environment as a result of anthropogenic activities such as automobile exhausts, agricultural and waste incineration, forest fires, coal, and spillage of crude oil to water and soil; or due to nature activities such as combustion of fossil fuels, and petroleum products (Sartoros et al., 2005; Haritash and Kaushik, 2009).

Removal of PAHs from the environmental contaminated sites is very important since most of them are known carcinogens and mutagens, as well as they, have many concerns to the public health (Grimmer et al., 1982;
Perera et al., 1998; Luch, 2005). These pollutants gave several direct and indirect harmful effects on the human according to (Vijayaraghavan and Shanthakumar, 2015). Physical, chemical, and biological strategies have been used to remove these PAH compounds from polluted sites (Riser-Roberts, 1998; Gan et al., 2009). However, these strategies are associated with some disadvantages such as high operation costs, low efficiency, and potential for secondary air or groundwater pollution due to the formation of toxic by-products. Biodegradation is an effective treatment strategy to remove $\mathrm{PAH}$ compounds from polluted sites because toxic microorganisms can decompose these organic substances into a simpler nontoxic product. By increasing in molecular weight of PAHs, the lipophilicity, environmental persistence, and genotoxicity increase. More specifically, pyrene is considered a genotoxic and bioaccumulative (Ahn et al., 2010). It has many toxic effects on both human and animal health such as reproductive difficulties and causing cancer. Therefore, the maximum contaminant limit of pyrene in drinking water has been established at $0.2 \mu \mathrm{g} / \mathrm{L}$ (Paria, 2008). Additionally, The US Environmental Protection Agency (EPA) has listed 16 PAHs, including pyrene (PY), among the 129 priority pollutants (Jin et al., 2007). During the past decades, several publications have reported that, pyrene can be degraded by different microbial species such as bacteria (Toyama et al., 2011; Hesham et al., 2014; Mawad et al., 2016), fungi (Hesham et al., 2017), plants (Liste and Alexander, 2000), and microalgae (Chan et al., 2006; Yan et al., 2014). Among the microalgal strain some chlorophyta like Scenedesmus platydiscus, Chlorella vulgaris,, Scenedesmus quadricauda, (Lei et al., 2007), chlorella sp. MM3 (Subashchandrabose et al., 2017) and Selenastrum capricornutum (Chan et al., 2006).

Cyanophyta and eukaryotic microalgae have three different ways to remove Polyaromatic hydrocarbons from the environment; 1) adsorption of PAHs on the surface of algal cells depending upon the active groups present on that sufaces, 2) accumulation of PAHs within the algal cells and 3) transformation of PAHs which depending upon the enzymatic actions. the third method of removal is considered the effective one due to get rid 
of PAHs toxcicity (Semple et al., 1999; El-Sheekh et al., 2012).

The kinetics of biodegradation is essential in the control of the bioremediation process (Lu et al., 2012). Biodegradation kinetics also provides a valuable explanation about the degradation pathways and reaction mechanisms. Therefore, application of kinetic data to the kinetic models provide an expectation of the rate at which a target toxic PAHs can be removed (Aryal and Liakopoulou-Kyriakides, 2013).

The major objective of this study is to evaluate the capability of two microalgal strains Oscillatoria sp. (Cyanophyta) and Chlorella sp. (chlorophyta) to degrade pyrene, determine the different concentrations of pyrene on the growth, dry weight and photosynthetic pigment contents of tested microalgae and to detect the most suitable model that describe PY biodegradation kinetics.

\section{Materials and methods}

\subsection{Biodegradation activity of algal strains on Pyrene}

Two microalgal species (Oscillatoria sp. and Chlorella sp.) have been used in our study were isolated from Assiut region (Egypt) and cultivated on BG 11 medium for one week at room temperature for enrichment and activation the cells. Algal cells $(O D 750=0.3)$ were dispersed into a fifty milliliters of sterile BG11 supplemented with acetonedissolved pyrene (PY) to a final concentration $50 \mathrm{mgL}^{-1}$ followed by evaporation of acetone with gentle shaking. After 5 days intervals, aliquots of $5 \mathrm{ml}$ were withdrown for determination the microalgal growth and degradation. Aliquots of BG11 medium containing algal cell without PY, served as the positive control. Cultures were incubated under the atmosphere condition at temperature $28 \pm 2{ }^{\circ} \mathrm{C}$, at $100 \mu \mathrm{mol}$ photons $\mathrm{m}^{-2} \mathrm{~s}^{-1}$ of continuous PAR light, and $100 \mathrm{rpm}$ agitation using a MiniOrbital Shaker (VWR, USA) for four weeks.

The growth of microalgae was monitored by OD 750 each experiment was carried out in duplicate and repeated twice, and the averages of four results were used for statistical analysis by T-test.

\subsection{Pyrene biodegradation percentage by HPLC}

Aliquots of algal growth sample $(5 \mathrm{ml})$ were withdrawn each 7 days extracted twice with an equal volume of ethyl acetate and passed through anhydrous sodium sulphate to get rid of any traces of water. The ethyl acetate extract then introduced to HPLC analysis (Hesham et al., 2014).

To determine the remaining concentration of PY, calibration standard was prepared by dissolving different concentrations of PY $(5-2000 \mu \mathrm{g} / \mathrm{ml})$ in ethyl acetate. Identification of the concentration of PY was performed using HPLC model Waters 600E equipped with autosampler waters 717 plus and dual wavelength UV detector model Waters 2487 (set at $254 \mathrm{~nm}$ ). The condition of operation was as follows: Column: SUPELCOSIL ${ }^{\mathrm{TM}}$ LC-PAH, $15 \mathrm{~cm} \times 4.6 \mathrm{~mm}, 5 \mu \mathrm{m}$ Injection volume: $2.0 \mu \mathrm{l}$. Mobile phase: acetonitrile $(\mathrm{A})$ : water (W) isocratic program, HPLC grade Water\%: $40 \%$ Acetonitrile\%: $60 \%$.
2.3. Effect of the initial PY concentration on microalgal growth

Five different concentrations of PY $(10,30,50,100$ and $200 \mathrm{mg} / \mathrm{L}$ ) were separately supplemented to the microalgal (BG11) medium to determine the influence of the initial concentration on cell density (OD750), dry weight, and photosynthetic pigment contents.

2.4. Determination of the photosynthetic pigments content

Total Chlorophyll and carotenoids were extracted and monitored from $2 \mathrm{ml}$ algal suspension by centrifugation and the growth media were decanted. Pigments were extracted in hot methanol for 10 minutes, according to the method described by (Marker, 1972). Cells debris was removed by centrifugation and the clear supernatant, which contains the pigments, was diluted to a definite volume. The absorbance was measured against methanol blank spectrophotometrically at the wavelengths of (663, 644 and $452 \mathrm{~nm}$ ). The concentrations of each pigment fraction (total chlorophyll and cartenoids) was expressed as $(\mu \mathrm{g} / \mathrm{ml})$ culture.

\subsection{Determination of dry weight}

Aliquots of algal suspension $(20 \mathrm{ml})$ were filtered above a glass fiber filter. The filter paper with algal cells was dried overnight in an oven at $80{ }^{\circ} \mathrm{C}$. After cooling reached to room temperature, they were reweighed and the dry weight was calculated. Data of dry matter contents were given as $(\mathrm{mg} / \mathrm{ml})$ algal suspension.

\subsection{Biodegradation kinetics of $P Y$}

The degradation kinetics of organic compounds pyreneby Microbial cells can be defined by following the kinetic equation (Jianlong et al., 2002):

$\gamma=\left(\gamma_{m} c\right) /(k+c)$

Where $\gamma$ is the biodegradation rate, $\gamma_{m}$ is the maximum specific biodegradation rate, $c$ is the substrate concentration, and $k$ is the half-saturation constant. If $\mathrm{c}<<\mathrm{k}$, Eq. 1 can be reduced to:

$\gamma=\left(\gamma_{m} c\right) / k$

Eq. 2 is a typical first-order biodegradation kinetic model. Assuming $k_{1}=(\gamma \mathrm{m} / \mathrm{k})$ and integrating it, Eq. (2) can be expressed as:

Inc $=\mathrm{a}+\mathrm{k}_{1} \mathrm{t}$

Where $k_{1}$ is the first order kinetic constant and $t$ is the time (per hour). The biodegradation half-life of first-order reaction can be also expressed as (Zeng et al., 2004):

$t_{1 / 2}=\ln 2 / k_{1}$

If $c>>k$, another simplified equation can be derived from Eq. (1):

$\mathrm{v}=\mathrm{\gamma}_{\mathrm{m}}$

Eq. (5) describes a zero-order biodegradation kinetic model and the biodegradation rate constant $k_{0}=\gamma m$. Thus, the relation of PY concentration with time is given as (Jianlong et al., 2002): 
$c=b+k_{0} t$

where $k_{0}$ is the rate constant for zero-order kinetics.

\section{Results and discussion}

\subsection{Growth of microalgae and degradation of $P Y$}

The time-courses of microalgal growth and PY degradation with an initial concentration of $50 \mathrm{mgl}-1$ were determined at $100 \mathrm{rpm}$ at $30{ }^{\circ} \mathrm{C}$. As shown in Figure $1 \mathrm{a}$ and b, the significant $(p \leq 0.05)$ increase in the algal biomass corresponding to the decrease of remaining concentration of PY was observed, after 30 days of incubation. However, the amount of PY removal by Oscillatoria sp. (95\%) was significantly $(p \leq 0.05)$ higher than the PY removal by Chlorella sp. (78.7\%).
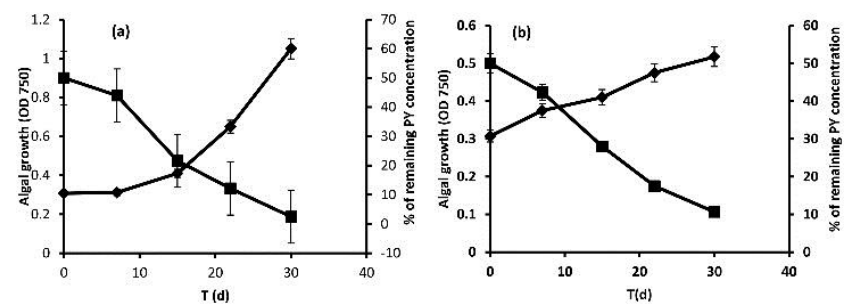

Figure 1. Time course of variation of microalgal growth (OD 750) and remaining Pyrene concentration $\left(\mathrm{mgL}^{1}\right)$ for Oscillatoria sp (a) and Chlorella sp (b) at $30 \mathrm{C}$ for 30 days in light

Many algal species are capable of growing heterotrophically on different organic sources (Semple et al., 1999). Many investigations discussed the role of algae on the degradation of crude oil components. Among these, the species of Chlorella sp. were widely used for biodegradation of pollutants (Subashchandrabose et al., 2014; Subashchandrabose et al., 2017). (Subashchandrabose et al., 2017) mentioned that, Species of Chlorella sp. do not utilize organic compounds as carbon sources, but they could degrade them during the detoxification process. Photodegradation of PAHs by photosynthetic microorganisms as microalgae has been very well established, and the source of light plays a crucial role in yielding photodegradation products (Subashchandrabose et al., 2014). In fact, the fluorescent light used in the present study might have little impact on photodegradation of PY as lately mentioned by (Subashchandrabose et al., 2017)

In this study, the efficiency of two microalgal strains Oscillatoria sp. and Chlorella sp. to degrade $50 \mathrm{mg} / \mathrm{L}^{-}$of PY was higher than the efficiency of Chlorella sp. MM3 (50 $\mathrm{MM}$ pyrene within 21 days in soil slurry system) that being combined with tween-80 used as a surfactant to make PY more available to the microalgae (Subashchandrabose et al., 2017). In addition to the degradation efficiency in this study was higher than some bacterial strains such as and Rhodococcussp $(0.08 \mathrm{mg}$ pyrene $\mathrm{mL}^{-1}$ day $^{-1}$ ) according to (Walter et al., 1991).

Regarding to the microalgal growth, the curve of Oscillatoria sp exhibited rapid growth rate and significant $(p \leq 0.05)$ higher algal biomass density (OD750=1.1) compared to Chlorella sp. (OD750=0.52), after 30 days of incubation. On the other hand, Chlorella sp. shifted the OD750 from 0.3 to 0.4 after 7 days of incubation which indicated short lag phase of 7 days, however this period extended to 14 days with Oscillatoria sp.

Zhao et al. (2005) used the optical density (OD. $750 \mathrm{~nm}$ ) in order to following up growth of the different species of microalgae. The use of OD to follow microalgal growth has the advantage of being fast for sub-culturing in particular medium. The cell density of Chlorella sp. Strain MM3 increased from $1.1 \times 105$ cells $\mathrm{mL}-1$ to $16.45 \times 105$ cells $\mathrm{mL}^{-1}$ within 7 days when it has been grown in presence of $50 \mu \mathrm{M}$ pyrene. The degradation of pyrene was dependent on the concentration of algal biomass used, the more the biomass, the higher the degradation percentages (Lei et al., 2006). In addition to biomass, cell density, cell wall composition and enzymes involved in $\mathrm{PAH}$ degradation might be important in determining the species-species variation in the degradation of pyrene (Lei et al., 2007).

\subsection{Effect of initial concentration on microalgal degradation efficiency}

The capability of both algal strains to degrade PY was separately tested in BG 11 medium consist of different initial concentrations of PY $(10,30,50,100,200 \mathrm{mg} / \mathrm{L})$. Results in Figure 2 showed that, generally, the biodegradation ability decreased with the increase of PY concentration. The two algal strains could completely remove PY (100\%) when the initial concentration of PY was 10 and $30 \mathrm{mg} / \mathrm{L}$. On the other hand, when the initial concentration of PY was ranged from $50-200 \mathrm{mg} / \mathrm{L}$, the biodegradation efficiency was significantly different. In addition to, the biodegradation efficiency of Oscillatoria sp. was significantly ( $\mathrm{s} \leq 0.05)$ higher than Chlorella $\mathrm{sp}$. at higher concentration of PY. The biodegradation efficiency of Oscillatoria sp. was 95, 83 and 68\% while for Chlorella sp. were 78, 66 and $49 \%$ when the initial concentration was 50, 100 and $200 \mathrm{mg} / \mathrm{L}$, respectively. Additionally, it was observed that, by increasing the initial concentration of Py, the algal growth decreased. The highest optical density was recorded at low concentration of $10-30 \mathrm{mg} / \mathrm{L}$ while the lowest one was recorded at initial concentration of $200 \mathrm{mg} / \mathrm{L}$. However, the growth of Oscillatoria sp. was significantly higher than Chlorella $s p$. at tested initial concentration as shown in (Figure 2).

The variation between two microalgal strain in the degradation capability is indicating the higher initial concentrations of PY constrain the biodegradation process (Ziagova and Liakopoulou-Kyriakides, 2007). This decreased biodegradation efficiency of Chlorella sp. can be attributed to extending substrate toxicity on microalgal cell systems of the culture at high concentrations (Chang and Alvarez-Cohen, 1995)

The biodegradability of PAHs appeared to be also related to microalgal initial cell density. Many literatures reported that, the initial cell density controlled the ability of algae to attack the aromatic ring. (Chan et al., 2006) reported that, the initial cell densities less than $10^{4}$ cells $\mathrm{mL}^{-1}$ of Selenastrum capricornutum were insufficient for PAHs 
biodegradation. Also, (Lei et al., 2006; Lei et al., 2007) observed degradation of PAHs was proportional increase with increasing cell densities of different green microalgae such as Scenedesmus platydiscus, Chlorella vulgaris, Selenastrum capricornutum, and Scenedesmus quadricauda.

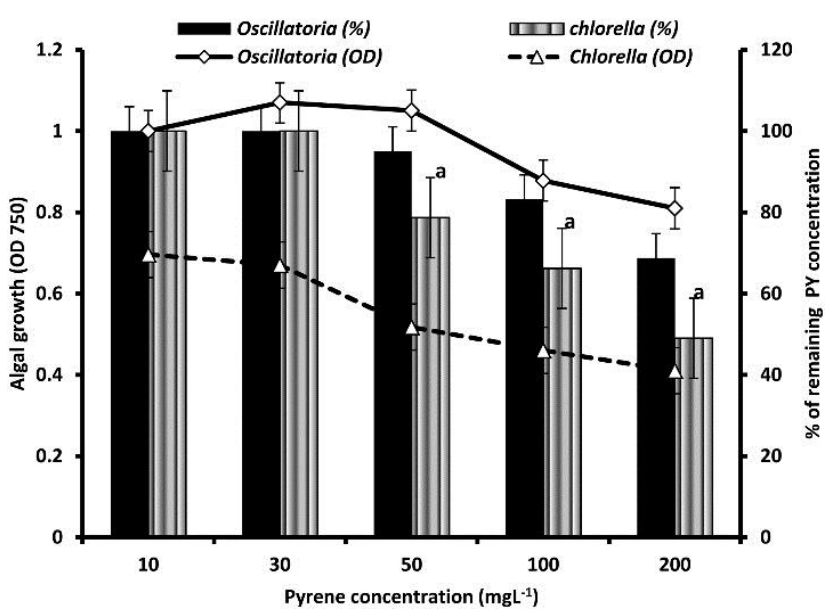

Figure 2. Microalgal degradation capability and growth (OD 750) at different PY concentration. ${ }^{a}$ Indicates statistically significant differences $(P<0.05)$ between the degradation percentage of Oscillatoria sp and Chlorella sp

\subsection{Effect of $P Y$ concentration on algal biomass and photosynthetic pigment contents}

The algal biomass contents such as dry weight $(\mathrm{mg} / \mathrm{mL})$, total chlorophyll and carotenoid $(\mu \mathrm{g} / \mathrm{mL})$ were determined as the methods described above. Figure $3 a$ and $b$ illustrated that, the dry weight of Oscillatoria sp. was significant higher than of Chlorella sp. but the total chlorophyll and carotenoid contents of the later were higher than Oscillatoria sp. at various concentrations of PY. The low concentrations of PY (10-30 mg/L) enhanced the growth of Oscillatoria sp. and significantly increased its dry weight and total chlorophyll however, there was no significant variation in the carotenoid contents at the different concentrations of PY (Figure 3a). Interestingly, the results of Chlorella sp. exhibited the highest dry weight, total chlorophyll and carotenoid contents at $50 \mathrm{mg} / \mathrm{L}$ of PY without any significant difference in these biomass contents in either higher or lower PY concentrations (Figure 3b). The increased in chlorophyll accompanied with increased in the dry weight due to Table 1. Biodegradation kinetics of pyrene of microalgal species (Oscillatoria sp. and Chlorella sp.)

\begin{tabular}{|c|c|c|c|c|c|c|c|c|c|}
\hline \multicolumn{5}{|c|}{ Oscillatoria sp. } & \multicolumn{5}{|c|}{ Chlorella sp. } \\
\hline \multicolumn{2}{|c|}{ Zero order kinetics } & \multicolumn{3}{|c|}{ First-order kinetics } & \multicolumn{2}{|c|}{ Zero order kinetics } & \multicolumn{3}{|c|}{ First-order kinetics } \\
\hline$k_{0}\left(h^{-1}\right)$ & $\mathrm{R}^{2}$ & $k_{1}\left(h^{-1}\right)$ & $t_{1 / 2}(h)$ & $\mathbf{R}^{2}$ & $k_{0}\left(h^{-1}\right)$ & $\mathbf{R}^{2}$ & $k_{1}\left(h^{-1}\right)$ & $t_{1 / 2}(h)$ & $\mathbf{R}^{2}$ \\
\hline 0.072 & 0.98 & 0.004 & 137.3 & 0.89 & 0.05 & 0.99 & 0.002 & 346.5 & 0.96 \\
\hline
\end{tabular}

The kinetic results of the biodegradation of PY by two algal strains were shown in Table 1 . As it can be revealed from this table, low correlation coefficient values $\left(R^{2}=0.89\right)$ was observed for first-order kinetics equation model at Oscillatoria sp. indicated that, this model was invalid with this strain however, it was valid with Chlorella increase in photosynthesis. Chlorophyll content represented the internal indicator of photosynthetic capacity of organisms (Takáčová et al., 2014).

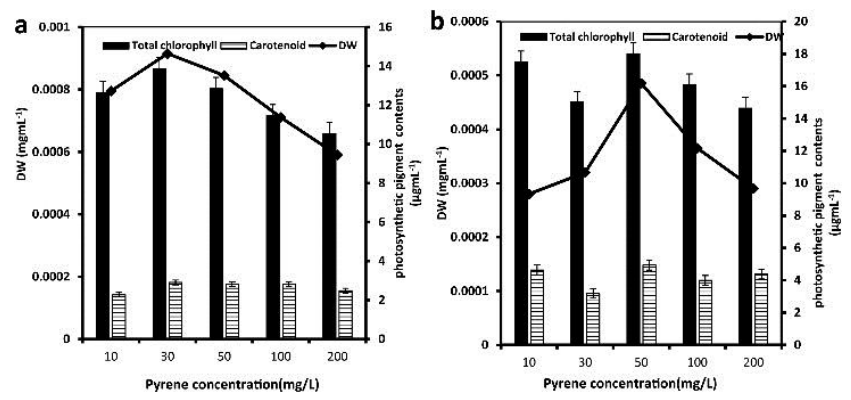

Figure 3. Effect of different initial PY concentrations on microalgal species Oscillatoria sp (a) and Chlorella sp (b) on microalga dry weight $(\mathrm{mg} / \mathrm{mL})$, total chlorophyll and carotenoid $(\mu \mathrm{g} / \mathrm{L})$ at $30 \mathrm{C}$ for 30 days in light

The biochemical changes in microalgal system that induced by PAHs are widely used for accessing the toxicity of this contaminants (Subashchandrabose et al., 2017). Pyrene was revealed to be toxic and stimulate stress responsive antioxidant reactions in several microalgae (Lei et al., 2006). The present study showed that the carotenoids which represent antioxidant substances were highly induced by Chlorella sp. at high concentration of PY although it did not serve as a stress indicator with Oscillatoria sp.

The water solubility and lipophilicity as well as the molecular weight, of the PAHs compounds affect the degradation capablity of microorganisms. The 4-ring PAHs, pyrene, were easier to be degraded by Selenastrum capricornutum than phenanthrene, a 3-ring PAH (Chan et al., 2006). Besides that, two flamentous fungi isolated from PAHs-contaminated soil, Coniothyrium sp. and Fusarium sp. preferentially decomposed high molecular weight PAHs (5-6 ring) than low molecular weight PAHs (Potin et al., 2004).

\subsection{The biodegradation kinetics of pyrene}

Biodegradation kinetic plays an important role in illustration the mechanisms of biodegradation as well as the reaction pathways. Application of experimental kinetic data to the kinetic models will be able to expect the rate of removal of toxic substance. sp. with high correlation coefficient value $\left(R^{2}=0.96\right)$. On the other hand, relatively high correlation coefficient values $\left(R^{2}=0.98\right.$ and 0.99$)$ suggested that, the biodegradation kinetics of both Oscillatoria $\mathrm{sp}$. And Chlorella sp. were well fitted with the zero-order kinetic equation model (Figure 4). 

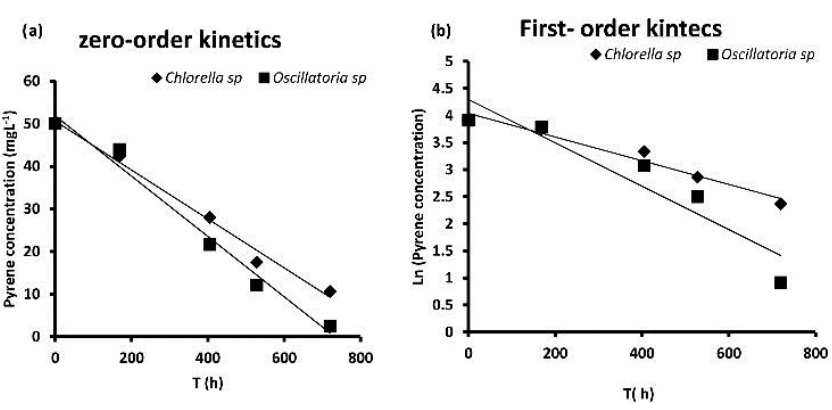

Figure 4. Zero and first-order kinetics equation ( $a$ and $b$ )

In addition to, the calculated zero-order rate coefficient $\left(\mathrm{k}_{0}\right)$ values of Oscillatoria $\mathrm{sp}$. was higher than Chlorella sp. sp (Table 1), indicating the rate of PY biodegradation of Oscillatoria sp. exceed Chlorella. sp Also, from the first order kinetics model, the calculated half-life biodegradation period of Oscillatoria sp. and Chlorella sp. extended to about 137.3 and $346.5 \mathrm{~h}$ (Table 1), respectively.

\subsection{The HPLC metabolitlic products}

The HPLC profile for PY and its metabolites were detected after 30 days of microalgal growth in BG11 medium that supplemented with PY. The HPLC chromatogram showed that there were five additional peaks that may indicate that there were five metabolic products. These peaks were detected due to PY degradation by Chlorella sp. while six metabolites were detected for Oscillatoria sp. as illustrated in (Figure $5 a$ and b). That means the rate of PY degradation in Oscillatoria sp. more in Chlorella sp. which accompanied with increased in rate of growth in Oscillatoria sp. in compared to Chlorella sp. That may be due to the increase in the smallest compounds which can use as nutrient for the algal growth. For that, the rate of growth increased with the increased of degradation of PY. As a consequence of breaking down of aromatic cycle, that produced organic acids. The biggest benefit of such systems can be described as the consumption of produced organic acids by microbial metabolism followed by subsequent synthesis of cell components and energy source (Takáčová et al., 2014).
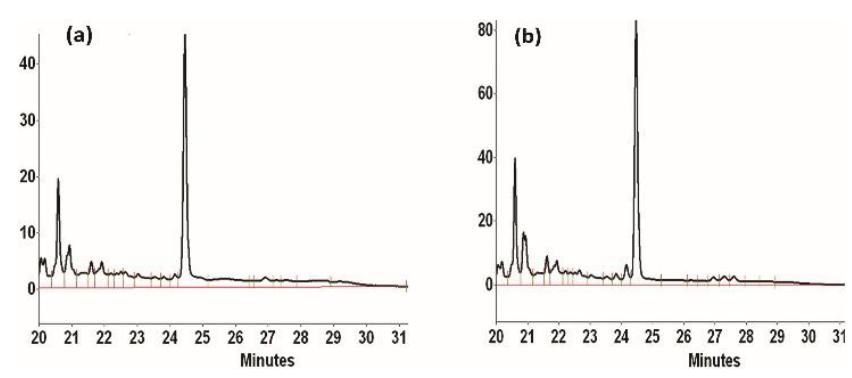

Figure 5. HPLC chromatogram of microalgal species Oscillatoria sp (a) and Chlorella sp (b) after 30 days of PY degradation

\section{Conclusion}

Pyrene was degraded by two different microalgal species Oscillatoria sp. and Cholrella sp. during 30 days of incubation. The first species exhibited higher biodegradation capability and higher growth parameters
(OD750, total cholorphyll, carotenoids and dry weight) in the presence of different concentrations of PY. Biodegradation kinetics of PY of both microalgal species followed the zero-order kinetic equation model.

\section{Acknowledgment}

This study was supported by Botany and Microbiology Department, Faculty of Science, Assiut University.

\section{References}

Ahn C.K., Woo S.H. and Park J.M. (2010), Surface solubilization of phenanthrene by surfactant sorbed on soils with different organic matter contents, Journal of hazardous materials, 177, 799-806.

Aryal M. and Liakopoulou-Kyriakides M. (2013), Biodegradation and kinetics of phenanthrene and pyrene in the presence of nonionic surfactants by Arthrobacter strain Sphe3, Water, Air, and Soil Pollution, 224, 1426.

Chan S.M.N., Luan T., Wong M.H. and Tam N.F.Y. (2006), Removal and biodegradation of polycyclic aromatic hydrocarbons by Selenastrum capricornutum, Environmental toxicology and chemistry, 25, 1772-1779.

Chang H.-L. and Alvarez-Cohen L. (1995), Model for the cometabolic biodegradation of chlorinated organics, Environmental science and technology, 29, 2357-2367.

El-Sheekh M., Ghareib M. and El-Souod G. (2012), Biodegradation of phenolic and polycyclic aromatic compounds by some algae and cyanobacteria, Journal of Bioremediation and Biodegradation, 3, 133.

Gan S., Lau E. and Ng H. (2009), Remediation of soils contaminated with polycyclic aromatic hydrocarbons (PAHs), Journal of Hazardous Materials, 172, 532-549.

Grimmer G., Dettbarn G., Brune H., Deutsch-Wenzel R. and Misfeld J. (1982), Quantification of the carcinogenic effect of polycyclic aromatic hydrocarbons in used engine oil by topical application onto the skin of mice, International archives of occupational and environmental health, 50, 95100.

Haritash A. and Kaushik C. (2009), Biodegradation aspects of polycyclic aromatic hydrocarbons (PAHs): a review, Journal of hazardous materials, 169: 1-15.

Hesham A.E.-L., Mawad A.M., Mostafa Y.M. and Shoreit A. (2014), Study of enhancement and inhibition phenomena and genes relating to degradation of petroleum polycyclic aromatic hydrocarbons in isolated bacteria, Microbiology, 83, 599-607.

Hesham A.E.-L., Mawad A.M., Mostafa Y.M. and Shoreit A. (2014), Biodegradation ability and catabolic genes of petroleum-degrading Sphingomonas koreensis strain ASU-06 isolated from Egyptian oily soil, BioMed research international, 2014.

Hesham A.E.-L., Mohamed E.A., Mawad A.M., Elfarash A., Abd ElFattah B.S. and El-Rawy M.A. (2017), Molecular characterization of fusarium solani degrades a mixture of low and high molecular weight polycyclic aromatic hydrocarbons, The Open Biotechnology Journal, 11.

Jianlong W., Xiangchun Q., Liping H., Yi Q. and Hegemann W. (2002), Kinetics of co-metabolism of quinoline and glucose by Burkholderia pickettii, Process Biochemistry, 37, 831-836.

Jin D., Jiang X., Jing X. and Ou Z. (2007), Effects of concentration, head group, and structure of surfactants on the degradation 
of phenanthrene, Journal of Hazardous Materials, 144, 215-221.

Lei A., Hu Z., Wong Y. and Tam N.F. (2006), Antioxidant responses of microalgal species to pyrene, Journal of Applied Phycology, 18: 67-78.

Lei A.-P., Hu Z.-L., Wong Y.-S. and Tam N.F.-Y. (2007), Removal of fluoranthene and pyrene by different microalgal species, Bioresource Technology, 98, 273-280.

Liste H.-H. and Alexander M. (2000), Plant-promoted pyrene degradation in soil, Chemosphere, 40, 7-10.

Lu J., Dang Z., Lu G., Yang C., Yi X. and Guo C. (2012), Biodegradation kinetics of phenanthrene by a fusant strain, Current Microbiology, 65, 225-230.

Luch A. (2005), The Carcinogenic Effects of Polycyclic Aromatic Hydrocarbons, World Scientific.

Marker A. (1972), The use of acetone and methanol in the estimation of chlorophyll in the presence of phaeophytin, Freshwater Biology, 2, 361-385.

Mawad A.M., Hesham A.E.-L., Mostafa Y.M. and Shoriet A. (2016), Pyrene degrading Achromobacter denitrificans ASU035: growth rate, enzymes activity, and cell surface properties, Rendiconti Lincei, 27, 557-563.

Paria S. (2008), Surfactant-enhanced remediation of organic contaminated soil and water, Advances in Colloid and Interface Science, 138, 24-58.

Perera F.P., Whyatt R.M., Jedrychowski W., Rauh V., Manchester D., Santella R.M. and Ottman R. (1998), Recent developments in molecular epidemiology: a study of the effects of environmental polycyclic aromatic hydrocarbons on birth outcomes in Poland, American Journal of Epidemiology, 147, 309-314.

Potin O., Rafin C. and Veignie E. (2004), Bioremediation of an aged polycyclic aromatic hydrocarbons (PAHs)-contaminated soil by filamentous fungi isolated from the soil, International Biodeterioration \& Biodegradation, 54, 45-52.

Riser-Roberts E. (1998), Remediation of Petroleum Contaminated Soils: Biological, Physical, and Chemical Processes, CRC press.

Sartoros C., Yerushalmi L., Béron P. and Guiot S.R. (2005), Effects of surfactant and temperature on biotransformation kinetics of anthracene and pyrene, Chemosphere, 61, 1042-1050.

Semple K.T., Cain R.B. and Schmidt S. (1999), Biodegradation of aromatic compounds by microalgae, FEMS Microbiology Letters, 170, 291-300.

Subashchandrabose S.R., Krishnan K., Gratton E., Megharaj M. and Naidu R. (2014), Potential of fluorescence imaging techniques to monitor mutagenic PAH uptake by microalga, Environmental Science \& Technology, 48, 9152-9160.

Subashchandrabose S.R., Logeshwaran P., Venkateswarlu K., Naidu R. and Megharaj M. (2017), Pyrene degradation by Chlorella sp. MM3 in liquid medium and soil slurry: Possible role of dihydrolipoamide acetyltransferase in pyrene biodegradation, Algal Research, 23, 223-232.

Subashchandrabose S.R., Wang L., Venkateswarlu K., Naidu R. and Megharaj M. (2017), Interactive effects of PAHs and heavy metal mixtures on oxidative stress in Chlorella sp. MM3 as determined by artificial neural network and genetic algorithm, Algal Research, 21, 203-212.

Takáčová A., Smolinská M., Ryba J., Mackulak T., Jokrllová J., Hronec P. and Čík G. (2014), Biodegradation of Benzo [a] Pyrene through the use of algae, Central European Journal of Chemistry, 12, 1133-1143.
Toyama T., Furukawa T., Maeda N., Inoue D., Sei K., Mori K., Kikuchi S. and Ike M. (2011), Accelerated biodegradation of pyrene and benzo [a] pyrene in the Phragmites australis rhizosphere by bacteria-root exudate interactions, Water Research, 45, 1629-1638.

Vijayaraghavan G. and Shanthakumar S. (2015), Efficacy of alginate extracted from marine brown algae (Sargassum sp.) as a coagulant for removal of direct blue2 dye from aqueous solution, Global Nest Journal, 17, 716-726.

Walter U., Beyer M., Klein J. and Rehm H.-J. (1991), Degradation of pyrene byRhodococcus sp. UW1, Applied Microbiology and Biotechnology, 34, 671-676.

Yan Z., Jiang H., Li X. and Shi Y. (2014), Accelerated removal of pyrene and benzo [a] pyrene in freshwater sediments with amendment of cyanobacteria-derived organic matter, Journal of Hazardous Materials, 272, 66-74.

Zeng F., Cui K., Li X., Fu J. and Sheng G. (2004), Biodegradation kinetics of phthalate esters by Pseudomonas fluoresences FS1, Process Biochemistry, 39, 1125-1129.

Zhao Y., Shi Y., Zhao W., Huang X., Wang D., Brown N., Brand J. and Zhao J. (2005), CcbP, a calcium-binding protein from Anabaena sp. PCC 7120, provides evidence that calcium ions regulate heterocyst differentiation, Proceedings of the National Academy of Sciences of the United States of America, 102, 5744-5748.

Ziagova M. and Liakopoulou-Kyriakides M. (2007), Kinetics of 2, 4-dichlorophenol and 4-Cl-m-cresol degradation by Pseudomonas sp. cultures in the presence of glucose, Chemosphere, 68, 921-927. 